\title{
Arbor
}

\section{Las propuestas comunitaristas en América y en Europa}

\author{
Concepción Naval y Alejo José G. Sison
}

Arbor CLXV, 652 (Abril 2000), 589-611 pp.

Se engloba bajo el título "comunitarismo» a determinados planteamientos en las ciencias humanas y sociales que reivindican el valor y la importancia de la persona, sociocultural e históricamente situada, frente al individuo, universal-abstracto y autónomo. La diversidad amplia de autores comunitaristas se auna en las críticas de la sociedad liberal-democrática. A pesar de las distintas tradiciones en las que se inscriben sus autores, hay grandes semejanzas entre el comunitarismo norteamericano y el comunitarismo europeo en sus propuestas para la formación de la identidad política, en contra de la desintegración social

Palabras-clave: crítica comunitaria al liberalismo, comunitarismo norteamericano, comunitarismo europeo.

La corriente denominada comunitarismo ${ }^{1}$ es un fenómeno que ha surgido en el mundo occidental, en el seno de las ciencias humanas y sociales, tanto en el ámbito anglo-americano como en el continental-europeo. Se manifiesta en el lenguaje, modo de razonar y propuestas realizadas en la política, la sociología y la ética, también en la economía, la psicología y la educación.

La ideología liberal ha interpretado - en términos generales- el hecho comunitario en relación con la emergencia de la modernidad. En cuanto el mundo moderno se constituye como tal, los lazos comunitarios comienzan a deshacerse en beneficio de modos de asociación más contractuales y modos de comportamiento más racionalistas e individuales. 
En esta óptica, la comunidad ${ }^{2}$ aparece como un fenómeno residual, que las burocracias institucionales y los mercados globales se encargarán de disolver. Todo acento sobre el valor de la comunidad se interpreta así, como supervivencia conservadora, o como nostalgia romántica y utópica, o como llamada a una forma u otra de colectivismo. Esta temática se desarrolla alrededor de las nociones de progreso, razón e individuo. Muchos autores han estudiado el vínculo social en relación con la noción de comunidad, poniendo ésta en ocasiones en oposición a la de sociedad. La conceptualización de los términos de Gemeinschaft (comunidad) y Gessellschaft (sociedad), es central para la sociología alemana de finales de siglo, después del trabajo fundador de Ferdinand Tönnies, aparecido en $1887^{3}$. Tönnies pone en relación estas dos nociones con los dos tipos de voluntad, la Wesenswille o voluntad esencial, natural y espontánea, y la Kürwille o voluntad arbitraria, racional y reflexiva ${ }^{4}$. Martin Buber introduce en 1900 una nueva distinción entre la antigua «comunidad de sangre» (Blutverwandtschaft) y la nueva «comunidad elegida» (Wahlverwandschaft), en tanto que Max Weber utiliza la noción de «comunitarización» (o comunalización) para describir el proceso de orientación mutua que se produce bajo el efecto de sentimientos comunitarios entre miembros de una polis dada. La misma dicotomía parece estar, en parte, en Durkheim en la oposición entre solidaridad mecánica y solidaridad orgánica. Esta se prolonga en los trabajos de G. Simmel, H. Plessner, T. Parsons y también de L. Dumont con el binomio holismo-individualismo. El declinar de la comunidad es por tanto un tema importante en aquéllos que contribuyeron a la fundación de la sociología en el siglo XIX.

Los pilares de este enfoque crítico de la noción de comunidad han hecho crisis recientemente. La ideología del progreso es la más afectada en cuanto sus promesas no se cumplen. Todo un conjunto de fenómenos ha provocado que el futuro inspire más inquietudes que esperanzas ${ }^{5}$ : los totalitarismos del siglo XX, la noción de límite puesta en boga por el ecologismo, el malestar que se ocasiona porque el nivel de vida no crece en la medida en que la mayoría lo espera y que las cosas materiales, por ellas mismas, no proporcionan sentido a la existencia humana.

A esta crisis de la ideología del progreso se une otra que afecta a la razón pura y al individuo abstracto. Toda la corriente postmoderna contesta la omnipotencia de la razón; Habermas rechaza la noción de razón trascendental, tal como la concibió la Ilustración; la razón es redefinida en relación con la finitud humana, lo que implica reconocer la naturaleza de un sujeto cognoscente. Se podría decir que de este esfuerzo por salvar la razón ha nacido la teoría de la ética comunicativa. Derrida por su lado, muestra que la razón está incrustada en las formas de vida y en la 


\section{Las propuestas comunitaristas en América y en Europa}

inconmensurabilidad de los juegos del lenguaje. H. G. Gadamer no es menos crítico hacia el racionalismo de la Ilustración y hacia lo que llama el «prejuicio contra los prejuicios» ${ }^{6}$. Dice que la razón no puede ser comprendida como aquello por lo que el hombre se libera de su contexto social-histórico, y define los «prejuicios» legítimos como aquellos destinados a facilitar la comprensión hermeneútica como modo primordial de la presencia humana en el mundo. Hay pues una historicidad de la creencia, una contextualización de la comprensión de la que no se puede prescindir. De hecho toda una serie de doctrinas y de filosofías contemporáneas ponen el acento en la contextualización del conocimiento y de la normatividad, sea en una óptica explícitamente anti-universalista, sea en nombre de una aproximación pluralista, que se acerca al relativismo.

Uno de los puntos problemáticos que la crítica filosófica y la argumentación política advierten es el reconocimiento de fisuras en el proyecto moderno; lo que Rorty llama el sueño de la «conmensuración universal» ${ }^{7}$, la búsqueda de un lenguaje unificado, de una matriz epistemológica universal $^{8}$. De este modo el pensamiento moderno se paraliza ante el desafío de articular de modo coherente la aspiración de universalidad y los imperativos de la contextualización que la filosofía práctica pide. Las diferentes respuestas buscan una reconstrucción del diálogo racional que integre las dimensiones teórica y práctica de la acción y mantenga abierta la tensión entre el plano contextualizado de la praxis humana y el plano -no ideal o desencarnado- de la reflexión. En este sentido, la comprensión de la racionalidad permitiría recuperar el ámbito de la filosofía práctica. En esta operación, la lectura comunitaria propugna una reconstrucción narrativa de las formas de vida que nos identifican como miembros de una comunidad cultural, partícipes -en concreto- de la tradición cultural y política occidental. El análisis de la racionalidad se lleva a cabo desde las coordenadas de una cosmovisión moral en las versiones aristotélico-tomista de MacIntyre, republicana de Sandel, democráticopluralista de Walzer o hegeliano-ilustrada de Taylor.

Las comunidades no solamente asocian a las personas sobre la base de un origen común o de características teóricamente heredadas por cada uno; constituyen grupos de géneros variados. La noción de identidad se despliega, de modo paralelo bajo la forma de una narrativa abierta, de tipo fundamentalmente dialógico. La problemática comunitaria suscita una investigación sobre el pluralismo y el «multiculturalismo» de las sociedades contemporáneas, en la perspectiva de un retorno a las pequeñas unidades de vida colectiva, huyendo de los grandes aparatos institucionales, burocráticos, que ya no desempeñan el papel tradicional de estructuras de integración. 
Bajo este último aspecto, la comunidad aparece como el marco natural de una democracia orgánica, directa, de base, fundada sobre una participación más activa y sobre la recreación de nuevos espacios públicos locales, al mismo tiempo que como una forma de resolver el mayor desafío que se ha lanzado en este fin de siglo: «cómo conseguir su integración y afirmar su identidad sin negar la diversidad y la especificidad de los diversos componentes» ${ }^{9}$.

Así la comunidad pierde el estatuto arcaico que la sociología le había atribuido; aparece como una forma permanente de asociación humana, que según las épocas, gana o pierde importancia. Jean-Luc Nancy lanzó una hipótesis según la cual la distinción entre las nociones de sociedad y comunidad sería un efecto de la modernidad.

En este marco, diseñado aquí a grandes rasgos, se puede situar la aparición y el desarrollo en América del Norte, desde los debates de los años 80 , de un movimiento que ha provocado una auténtica avalancha de debates; pero en los que Europa —en opinión de Benoist $(1994)^{10}$ — ha estado informada de los principios que estaban en juego (la corriente liberal —J. Rawls, R. Dworkin-y la corriente libertaria -R. Nozick, M. Rothbard-) pero descubrió recientemente este «movimiento» comunitarista.

\section{1. ¿«Comunitarismo norteamericano» $\mathbf{y}$ «comunitarismo europeo»?}

Hasta aquí, hemos hecho una analítica histórico-temporal o "genética», basada en las «biografías intelectuales» de los autores tildados de «comunitaristas» y de sus contrincantes, reunidos en torno al liberalismo democrático. En principio, nada obsta para que se pudiera intentar también otro tipo de análisis, geográfico-espacial o a simultaneo de los mismos autores: ¿tiene sentido preguntarse por posibles diferencias entre un "comunitarismo norteamericano» y un "comunitarismo europeo»?

Nuestra hipótesis es que la respuesta a la pregunta anterior no es indiferente al planteamiento que uno haya asumido como propio, sea éste filo-comunitarista o más cercano al liberal. Es decir, la combinatoria de las respuestas posibles revela la postura elegida por uno en este debate. La pregunta no puede contestarse «objetivamente» o en abstracto. El que se adhiere al liberalismo, llevado por su universalismo, siempre se inclinará a negar, o al menos, minimizar las diferencias, mientras que el comunitarista, dotado de mayor sensibilidad por lo idiosincrático y particular, se esforzará por afirmar y reivindicarlas. 
El comunitarista, como primera reacción, podría intentar establecer un criterio físico o geográfico entre el comunitarismo norteamericano y el comunitarismo europeo. Al principio podría dejarse llevar por la falsa impresión de que las líneas divisorias continentales fueran suficientes para demarcar o delimitar el pensamiento. Pero pronto se daría cuenta de su equívoco: esas líneas divisorias, en realidad, no existen; no son más «reales» en el mundo físico o natural que en el mundo mental; son también «constructos», «artificios», objetos de decisiones humanas históricas, y hasta cierto punto, arbitrarias. Tendría que reconocer entonces que la «patria» o el origen, la «nacionalidad» o el estado actual y el desarrollo futuro de las ideas, como el mismo comunitarismo, necesariamente pasan por la patria, la nacionalidad y los proyectos «políticos» —en sentido amplio- de sus pensadores.

Tarde o temprano el investigador comprometido tendría que preguntarse quiénes son los comunitaristas norteamericanos y quiénes son los comunitaristas europeos. Tendría que hacerlo a la vez que establece o define su comprensión particular y peculiar de la «norteamericaneidad»y del «europeísmo». Está claro que no se trata de un asunto cerrado, sino de uno indefinidamente abierto a la discusión, en gran parte, como todo lo cultural. Pero el admitir una distinción de grados, de un más y un menos, con respecto tanto a la «norteamericaneidad» como al «europeísmo», no significa renunciar a saber qué es lo «norteamericano», qué lo «europeo», antes bien lo presupone. Para saber si un determinado pensador es un comunitarista norteamericano o un comunitarista europeo, el hipotético investigador averiguaría, ante todo, su nacionalidad o ciudadanía, y también para esto hay todo una gama de posturas razonables.

Es difícil, por no decir imposible, aclarar el sentido y la relación entre la ciudadanía y la nacionalidad sin referirse simultáneamente a la comunidad, a la sociedad (civil) y al estado. (Huelga decir que todos estos conceptos son objetos de fuertes debates entre comunitaristas y liberales.) De entrada, nos atreveríamos a afirmar que la ciudadanía, al igual que la comunidad política o sociedad (civil) de la que depende, son conceptual y quizás también históricamente anteriores a la nacionalidad y al estado.

Según una versión republicana amplia y originaria, la ciudadanía se concibe como el vínculo político por antonomasia; es la relación social que vincula entre sí a los miembros de una comunidad política, en cierto modo, constituyendo esta misma en una sociedad (civil). La ciudadanía se ejerce mediante la participación en el discurso público, en la decisión conjunta de asuntos que conciernen a toda la comunidad o sociedad. El tomar parte de esta decisión, aparte de ser expresión de la propia liber- 
tad y dignidad humana, se considera también como una actividad que es «fin en sí misma»; es decir, valiosa, independientemente de otras referencias.

Se llama «estado» a la comunidad política o sociedad a la que una persona se vincula en condición de ciudadano, al adquirir ésta una forma legal o jurídica en el presente. $\mathrm{El}$ estado, por medio de leyes, garantiza al ciudadano la protección de sus derechos. El ciudadano, a su vez, debe al estado el reconocimiento de su poder y autoridad soberanas, en una actitud estable de obediencia y lealtad. La ciudadanía se concreta ahora en una relación jurídica: la persona es sujeto de derechos reivindicables ante el estado y de deberes para con el mismo.

Históricàmente, el estado había evolucionado hasta tomar la forma del llamado «estado-nacional». Junto con los vínculos jurídicos en el presente, el «estado-nación» presuponía una homogeneidad o identidad de sangre (raza, etnia), tierra de origen o nacimiento (territorio), lengua o idioma (cultura) y creencia o religión (pasión) entre las personas que lo integraban. Como consecuencia, la ciudadanía recibía todas estas determinaciones ulteriores convirtiéndose en «nacionalidad». Tanto por su naturalismo aparente, como por su disposición orgánica, el estado-nación era la modalidad de comunidad política o sociedad preferida por el romanticismo.

La «piedra de escándalo» para cualquier éstado siempre ha sido la participación política. En principio, ésta compete; por derecho, a todos los ciudadanos. Pero en la práctica, por el gran tamaño del estado, por el número elevado de ciudadanos, por las dificultades intrínsecas a la comunicación humana, etc., es imposible que todos los ciudadanos participen libremente y por igual en la tarea esencial e importantísima de la decisión de los asuntos públicos. Hay muchas voces ciudadanas - quizás incluso la mayoría - que están silenciadas: ya no hablan, y si hablan, no se les oye, y si se les oye, no se les escucha. Se ahogan sus voces - a pesar de la presunta representación- en la burocracia administrativa, tan técnicamente ingeniosa y necesaria, en cuanto resultadö de mayor objetividad y racionalización, como también a veces, tan cruel, inhumana, manipulable e ineficaz. La relación jurídica sofoca los otros vínculos más vitales que unen el ciudadano al estado. El ciudadano sólo periódicamente rompe su silencio con la emisión del voto anónimo.

El ciudadano sufre una segunda alienación política, además de aquella efectuada por la definición puramente legal de su vínculo con el estado, cuando el estado se erige en un omnipresente «estado de bienestar»o «estado-providencia». La provisión directa por parte del estado de los «derechos de bienestar» al ciudadano actúa como, una especie de sordina o 


\section{Las propuestas comunitaristas en América y en Europa}

mordaza que le calla en el discurso público. Las leyes ya no se orientan hacia la consecución del bien común, políticamente definido, sino hacia la protección y el fomento de intereses económicos privados, disfrazados esta vez como «derechos de bienestar». Al criterio jurídico de la ciudadanía, que es el derecho al voto, se añade, con su peso específico propio, el criterio económico de tener "propiedad» (inmuebles, dinero, crédito, acciones, trabajo, especialmente para un funcionario, etc.) o el derecho a ella, en el caso de las clases sociales pasivas. El estado ya no se distingue apenas de una empresa privada, con ánimo de lucro para los cargos electos y burócratas, que procura tener al ciudadano-cliente satisfecho, al menos hasta las elecciones próximas.

En la versión de «estado-nación», aparte del ya mencionado problema de la participación política, surge otro conocido con el nombre genérico de «multiculturalismo». ¿Qué hacer cuando la homogeneidad de tierra, sangre, lengua y religión ya no se da en una población en el territorio de un estado? ¿Qué derechos habría que reconocerles y garantizar a las minorías en un «estado plurinacional»?

Por último, el ocaso de las ideologías, la liberalización de los mercados y el desarrollo de la tecnología de la telecomunicación y de la informática han creado el ambiente propicio para la globalización. La globalización apunta - teóricamente - al fin del estado nacional como consecuencia del fin de la «economía nacional». La soberanía se traslada, en principio, del estado nacional, pasando por los mercados regionales o los mercados de bloques, a un mercado global único. En efecto, dejaríamos de ser ciudadanos, cada cual de su propia nación o país, dejaríamos de tener «nacionalidad», para convertirnos en agentes económicos cosmopolitas, ya sea como productores o vendedores, ya sea como consumidores o compradores. Entonces sí que experimentaríamos por fin lo que hasta ahora sólo ha sido una promesa, la de una libertad máxima y eficaz, gentileza del mercado, en ausencia del estado.

Incluso si por arte de magia, se consiguiera sortear todas las dificultades teóricas planteadas para determinar la ciudadanía y la nacionalidad del comunitarista ficticio, todavía quedarían bastantes problemas prácticos. ¿Qué criterio utilizaríamos para averiguar su ciudadanía o nacionalidad? ¿El «documento nacional de identidad»? Algunos países no lo tienen; y en otros, existen barreras constitucionales para que el estado se lo expidiera a los ciudadanos. ¿El pasaporte? Los países de la Unión Europea ya lo tienen en común; y a sus ciudadanos — como a los ciudadanos norteamericanos y canadienses - ya no se les exige para traspasar sus respectivas «fronteras». ¿El carnet de votante? Los ciudadanos comunitarios europeos ya tienen elecciones comunes, en las que cualquiera de 
ellos puede ser sujeto activo o sujeto pasivo de voto, indistintamente de su nacionalidad. En el caso de norteamérica, menos del 50\% de los ciudadanos ejercen su derecho al sufragio, y probablemente no tendrán semejante documento. ¿La declaración de la renta? ¿Acaso la única función que queda al estado es la de recaudar, para luego poder despilfarrar, los impuestos? Pero hay muchos tipos de impuestos (directos, indirectos), y muchos modos de cobrarlos (en el origen, en el último eslabón en la cadena de transacciones). Además, existe una proliferación de tratados fiscales bilaterales y multilaterales entre estados, y los más ricos siempre consiguen evadir o evitar los impuestos mediante sociedades registradas en paraísos fiscales.

Parece que sólo nos quedarían documentos tan poco fiables o de uso tan restringido como la cartilla militar (¿qué pasa si es un «casco azul», de la OTAN, o de alguna otra fuerza multinacional?) o el carnet de conducir (se expiden en Norteamérica mayormente para poder consumir bebidas alcohólicas). ¿Estaríamos dispuestos a que de ellos dependieran si un pensador determinado es norteamericano o europeo? Y luego, habría que defender la influencia de la ciudadanía o la nacionalidad en el pensamiento de un autor, en concreto, en la versión que él cultiva del comunitarismo. Tendríamos que establecer si dicha influencia es lo suficientemente significativa y consistente, tanto para un autor como para los de su supuesto grupo, como para constituirse en seña de identidad; en definitiva, saber si tal influencia genera una «tradición».

\section{Primacía liberal de la justicia sobre el bien}

En este panorama conviene no perder de vista la afirmación que es paradigmática de la teoría liberal contemporánea: la teoría de la justicia como equidad de John Rawls en su libro A Theory of Justice. También convendría examinar las más recientes versiones de su posición, que es llamada comúnmente, 'el nuevo Rawls', que consiste en el intento de formular una posición liberal que es sensible a los aspectos de la crítica comunitaria.

La teoría liberal se presenta en primera instancia como una teoría de los derechos, fundada sobre una antropología de tipo individualista ${ }^{11}$. Este individualismo ${ }^{12}$ se presenta a sí mismo - paradójicamente-como un universalismo en virtud de un postulado de igualdad que se apoya en una definición abstracta de los agentes. En la óptica del «individualismo posesivo" (Macpherson), cada individuo es considerado como un agente moral autónomo, "propietario absoluto de sus capacidades» ${ }^{13}$, que usa 


\section{Las propuestas comunitaristas en América y en Europa}

para satisfacer los deseos expresados en sus elecciones. La hipótesis liberal apunta de este modo al individuo separado, existente como un todo completo en sí mismo, que busca maximizar sus ventajas a través de las elecciones libres, voluntarias y racionales, sin que éstas sean resultado, fundamentalmente, de influencias, experiencias, contingencias y normas propias del contexto social y cultural. Los individuos poseen, por su naturaleza autónoma, los derechos que la teoría liberal considera como inalienables e imprescindibles. Estos son los derechos que podemos llamar «prepolíticos».

De este modo, ninguna «pertenencia a» será constitutiva del individuo, bajo pena de atentar contra su autonomía; sólo pueden existir asociaciones voluntarias, contractuales, resultantes de la voluntad de los agentes al perseguir sus intereses. Los libertarios llegan a afirmar una «prioridad ontológica» de los derechos sobre las preferencias, indicando que los derechos no pueden ser alienados incluso aunque los titulares consientan bajo el pretexto de que resultará para ellos un aumento de su bienestar o de su satisfacción. En todo caso el triunfo de estos derechos es lo que importa sobre toda otra consideración observándose una falta de simetría entre derechos y deberes liberales, ya que los derechos se derivan de una naturaleza humana que no tiene necesidad de otro para existir -el hombre tiene los derechos del estado de naturaleza-, pero no hay deberes más que en el estado social; los derechos serían completos en ellos mismos, en tanto que los deberes son por definición incompletos. Se deduce que la obligación moral es puramente contractual y que la sociedad tiene siempre más deberes hacia los individuos - para empezar el deber de garantizar sus derechos- que éstos tienen con ella.

Precisamente la importancia dada a los derechos explica el carácter imperativo y deontológico (en el sentido kantiano del término) de la moral liberal: la teoría liberal sitúa lo justo (right) por encima del bien (good), y de lo justo se deriva un número de obligaciones categóricas que afectan incondicionalmente a todos los agentes, sean cuales sean sus rasgos particulares, pertenencias o compromisos. El debate sobre la prioridad de lo justo o del bien (right vs good) es central hoy en el debate filosófico, político y moral americano ${ }^{14}$. Esta prioridad de lo justo sobre el bien aparece en J. S. Mill y en Kant. Fue impugnada esta prioridad por Hume, Schopenhauer, Hegel, y más recientemente por E. Anscombe y P. Foot.

Si la justicia se funda sobre una concepción singular de bien, aquélla llegará, según S. Mill, a imponer preferencias a ciertos ciudadanos, lo cual entorpecería la búsqueda de la utilidad, y según Kant, llegaría a esclavizar a los individuos a la irracionalidad, ya que ninguna concepción 
del bien sería objeto de un consenso fundado en razón ${ }^{15}$. Es esta idea de la prioridad de lo justo sobre el bien la que es retomada por la teoría liberal moderna. J. Rawls al mismo tiempo que busca desligar el proyecto kantiano de su anterior planteamiento idealista, apoyándose en la concepción trascendental del sujeto - de ahí su recurso a la ficción metódica de la «posición original»-, define la justicia como «la virtud primaria de las instituciones sociales». Lo justo se constituye por sí mismo, bajo el efecto de la voluntad de justicia, y no por conformidad a una idea de bien. «El concepto de justicia, es independiente del concepto de bien y anterior a él, en el sentido en que sus principios limitan las concepciones de bien autorizadas» ${ }^{16}$.

Rawls parte de la pregunta: ¿cómo debe ser la sociedad para que sea justa ${ }^{17}$. De algún modo su respuesta es una alternativa al modelo de justicia utilitarista, dominante en la tradición occidental, apoyándose en una línea de pensamiento contractualista propia de la Ilustración. Sus inspiradores fundamentales al pretender elaborar una teoría «sustantiva» de la justicia son Locke, Rousseau y Kant ${ }^{18}$. Así la noción de persona moral que Kant defendió en la Fundamentación de la Metafísica de las Costumbres constituye la idea principal que Rawls tiene en mente a la hora de elaborar su Theory of Justice y que se había insinuado en algunos párrafos de los artículos que le precedieron ${ }^{19}$.

Se percibe la presencia implícita del imperativo categórico kantiano - que impele a considerar a las personas como fines en sí mismas- en las distintas partes de la teoría rawlsiana: a) en la determinación de la posición original, b) en los contenidos de los principios de justicia, c) en las críticas al utilitarismo clásico, y d) en la interpretación kantiana de su teoría. Podemos pensar, que es la misma ética de Kant - y no sólo su contractualismo político - la que ofrece el mejor respaldo filosófico a la teoría de Rawls porque es, sin duda, la ética que mejor fundamenta, desde la razón, la dignidad de la persona, que subyace a todo el proyecto rawlsiano.

De todas formas, conviene no perder de vista que en el pensamiento de Rawls se observa una evolución - aunque no ha sido un cambio sustancial- tal como se comprueba en su obra Political Liberalism ${ }^{20}$. Es un nuevo enfoque del proyecto emprendido en Theory of Justice que denomina: liberalismo político. La fundamentación ahora es histórica y política. Los bienes primarios son así los bienes de los ciudadanos libres e iguales en la esfera política; lo que necesitan los ciudadanos de un régimen liberal. El problema es que el liberalismo es a la vez una teoría comprensiva y una práctica política. La «concepción política» debe cumplir dos requisitos: las instituciones políticas deben ser concebidas de tal 
modo que no sólo cumplan los requisitos de la justicia sino que tambiél. satisfagan la necesidad de estabilidad política y unidad de una sociedad liberal. Así el consenso no es simplemente un límite puesto en el empleo de la «razón pública», sino un fin de las instituciones políticas. En esta nueva obra, proporciona una corrección al apriorismo de Theory of Justice.

La misma idea de la prioridad de la justicia respecto al bien aparece en R. Nozick, B. Ackermann y R. Dworkin; es un rasgo de la concepción liberal de los derechos. Estos derivan de la «naturaleza» de los agentes, no de sus méritos o de sus virtudes, que no son más que atributos contingentes de su personalidad; no pueden revelarse más que desde una noción abstracta de la justicia, no desde una concepción previa del bien o de la vida buena. Con referencia a estos derechos, lo justo prima sobre el bien en importancia, ya que los derechos individuales no pueden sacrificarse jamás al bien común; y desde un punto de vista conceptual, porque los principios de justicia que los especifican no pueden fundarse sobre una concepción particular de bien. La dignidad individual constituye un absoluto que no puede sacrificarse por posibles ventajas sociales, ni por ningún otro interés general o bien común ${ }^{21}$. La crítica de esta noción de bien común se relaciona con la antropología individualista; la sociedad no es más que una adición de individuos, es decir de átomos sociales sepa$\operatorname{rados}^{22}$.

\section{Crítica comunitaria al liberalismo}

Interesa destacar los principales pensadores que se consideran habitualmente, en una primera etapa histórica, como críticos comunitaristas del liberalismo: M. Sandel, A. MacIntyre, Ch. Taylor y M. Walzer, e identificar los temas que estos teóricos tienen en común, así como los caminos en los que difieren, ya que este movimiento intelectual, lejos de constituir un conjunto unificado, se presenta sobre todo como una constelación en la que quizá los principales representantes que se suelen destacar son los filósofos mencionados, con excepción del caso de M. Walzer, que aunque se le asocia al punto de vista comunitarista, algunos autores hacen una consideración diferente de su pensamiento.

Alrededor de ellos se pueden situar una gran cantidad de autores -aislados algunos de ellos - pero cuyos trabajos se sitúan en la temática comunitarista, como R. M. Unger, J. Finnis, M.A. Glendon, A. Etzioni ${ }^{24}$, etc. En un tercer nivel, podrían estar, entre otros, autores como R.N. Bellah y colaboradores y también C. Lasch, que sin reclamar para ellos el título comunitarista, tienen similares preocupaciones (crítica del «narcisismo»en 
C. Lasch, de la «tiranía del mercado» en R.N. Bellah). Del mismo modo es destacable junto a las obras de estos autores, los numerosos artículos y libros que se han consagrado a este tema ${ }^{25}$. Por último, sería enriquecedor prestar atención a algunos teóricos descritos como «liberales comunitaristas», tal es el caso de R. Rorty y J. Raz. Una consideración completa de este fenómeno reclamaría un desarrollo que no es posible realizar aquí completamente dada la masiva cantidad de bibliografía existente.

Un problema básico que surge al iniciar este estudio es la misma terminología utilizada ya que tanto «liberalismo» como «comunitarismo» significan realidades diversas en los diferentes autores. Dado esto, sería importante que fuéramos capaces de identificar las diferencias entre la crítica comunitaria y otras críticas realizadas, pero aquí las cosas son muy complejas de nuevo. Por ejemplo, ante la pregunta de si el comunitarismo es necesariamente conservador en sus implicaciones, aunque cabe la respuesta de que algún comunitarista tiene una posición que conduce a demandas bastante radicales de cambio social y político, hay afinidades entre esas dos áreas de pensamiento. De modo similar, las relaciones etimológicas entre 'comunitarismo' y 'comunismo' sugieren que nuestra área de intereses puede solaparse con la crítica marxista al liberalismo.

La crítica comunitaria cuestiona la prioridad dada al individuo sobre la comunidad en el pensamiento liberal y se presenta a sí misma como un rechazo al énfasis liberal en la libertad del individuo. Surge aquí una cuestión sugerente: las relaciones entre el liberalismo contemporáneo y el comunitarismo y las tradiciones intelectuales de las cuales emanan. Cuando pensamos en la tradición liberal, pensamos en teóricos tales como, Locke, Kant y Mill, cada uno de los cuales hace una contribución diferente a la herencia del liberalismo moderno. En la vertiente comunitaria, nuestra vista puede dirigirse a Aristóteles, Hegel e incluso a Gramsci, aunque aquí, como la gran heterogeneidad de la lista sugiere, no hay una conciencia propia de tradición.

El objetivo del movimiento comunitario es enunciar una nueva teoría combinando estrechamente filosofía moral y filosofía política. Aunque tiene un alcance más amplio, esta teoría se ha elaborado a partir de los años 80 , con referencia, por una parte, a la situación particular de los EE.UU. que está marcada por una verdadera inflación de la política de los «derechos», por la disgregación de las estructuras sociales, la crisis del Estado-Providencia y la emergencia de la problemática «multiculturalista», y por otra parte, como reacción a la teoría política liberal reformulada en el curso de la década precedente por autores como R. Dworkin, B. Ackerman y sobre todo J. Rawls. 


\section{Las propuestas comunitaristas en América y en Europa}

El punto de partida de la crítica comunitaria es de orden sociológico y empírico $^{26}$. Los comunitaristas constatan, observando las sociedades contemporáneas, la disolución del nexo social y de las identidades colectivas, el incremento del individualismo y en consecuencia, la generalización de una falta de sentido. Estos fenómenos son, por una parte, los efectos de una filosofía política que: provoca la atomización social legitimando la búsqueda del propio interés, fomentando mirar al otro como un rival, o al menos como un enemigo potencial; defiende una concepción desencarnada del sujeto, sin tener en cuenta que los compromisos y pertenencias son también constitutivos de su yo; aboca al olvido de las tradiciones -en nombre de un universalismo abstracto- y a la erosión de modos de vida diferenciados; no ve en la sociedad más que una «empresa cooperativa fundada sobre la ventaja mutua» y niega la existencia del bien común ${ }^{27}$. Bajo una aparente intención de «neutralidad» genera escepticismo moral y se hace insensible a las nociones de pertenencia, valores comunes y destinos compartidos.

De todas formas, cabe plantearse si el comunitarismo posee realmente un cuerpo de doctrina positiva o es más bien un intento de reunir un conjunto de «críticas al liberalismo», desde muy diversos ángulos, que no poseen una unidad cierta y más bien les une un sentido negativo. De hecho parecen seguir usando el mismo lenguaje o esquemas de pensamiento liberal y se puede poner en duda si resuelven, de hecho, algunas de las dificultades que plantean como, por ejemplo, la superación del relativismo. Los esfuerzos de autores como Etzioni parecen querer responder que sí. Este autor, en su libro, Rights and the Common Good indica las que serían las dos cuestiones comunitaristas centrales: el equilibrio entre los derechos individuales y las responsabilidades sociales; y el papel de las instituciones sociales que alimentan los valores morales dentro de las comunidades ${ }^{28}$.

Las críticas que los comunitaristas dirigen al liberalismo, tanto por lo que se refiere a la filosofía política, como a la concepción general de hombre y sociedad son múltiples ${ }^{29}$. El liberalismo - denuncian los comunitaristas - desatiende y hace desaparecer las comunidades intermedias, que son un elemento fundamental e irreemplazable de la existencia humana. Devalúa la vida civil al considerar la asociación política como un simple bien instrumental, sin ver que la participación de los ciudadanos en la comunidad política es un bien intrínsecamente constitutivo de la vida buena. Es incapaz de dar cuenta de manera satisfactoria de un cierto número de obligaciones y compromisos - tales como los que no resultan de una acción voluntaria o de un compromiso contractual- como las obligaciones familiares, el servicio al país o la prioridad del bien común al interés individual. Propaga una concepción errónea del yo ${ }^{30}$, negándo- 
se a admitir que éste siempre está situado en un contexto socio-cultural e histórico y, constituido, en parte al menos, por valores y compromisos que no son ni objetos de elección ni revocables a voluntad. Suscita una inflación de la política de derechos (reclamar derechos buscando maximizar sus intereses sin tener en cuenta si es en detrimento de otros), y produce un nuevo tipo de miembro de la sociedad, el «individuo dependiente» (Fred Siegel), al mismo tiempo que un nuevo tipo de sistema institucional, la «república procedimental» (M. J. Sandel). Exalta la justicia como la «virtud primera de las instituciones sociales» ${ }^{31}$. Y en fin desconoce, debido a su formalismo jurídico, el papel central que juegan la lengua, la cultura, las costumbres, las prácticas y los valores compartidos, como bases de una verdadera «política de reconocimiento» (politics of recognition) de las identidades y de los derechos colectivos.

Para los comunitaristas, el hombre se define ante todo como un «animal social y político». A partir de ahí, la igualdad se define no como aquello que queda del individuo una vez que se ha hecho desaparecer todo lo que le religa a un contexto socio-histórico dado, sino como lo que resulta de la libre expresión de la identidades constituidas y situadas en su contexto. Los derechos no son atributos universales y abstractos, producidos por una «naturaleza» distinta del estado social y que formarían por ellos mismos un dominio autónomo, sino la expresión de valores propios de las colectividades o de los grupos diferenciados -en este sentido, el derecho de un individuo a hablar su lengua es indisociable del derecho a la existencia de un grupo que la practica-, al mismo tiempo que el reflejo de una teoría más general de la acción moral o de la virtud. La justicia se funde con la adopción de un tipo de existencia (la vida buena) ordenada a las nociones de solidaridad, reciprocidad y bien común. La «neutralidad» que se proclama en el Estado liberal se considera ilusoria y desastrosa en sus consecuencias.

En cuanto al método intelectual empleado, el punto de vista comunitario aparece próximo tanto a la hermeneútica - que insiste en la forma en que los hechos sociales son siempre «construidos» en un proceso de interpretación-, como a ciertos autores de la Escuela de Frankfurt Adorno principalmente-, hasta al pragmatismo de un R. Rorty - por su «construccionismo social» ${ }^{32}$ y la importancia que da a la noción de solidaridad $^{33}$ - . Sin embargo, son diversos los aspectos en los que cada uno de los autores insisten, según su propio bagaje intelectual; nos encontramos así con una gran variedad de perspectivas en la crítica comunitarista, y no es posible abarcarlas en su totalidad.

Una comunidad auténtica no es pues - afirman los comunitaristasuna simple reunión o adición de individuos. Sus miembros tienen, en tan- 


\section{Las propuestas comunitaristas en América y en Europa}

to que tales, fines comunes ligados a los valores o a las experiencias compartidas, y no solamente a intereses privados más o menos congruentes. Estos fines son propios de la comunidad misma, no son objetivos particulares que resultan ser los mismos en la mayor parte de sus miembros. En una simple asociación, los individuos miran sus intereses como independientes y potencialmente divergentes los unos de los otros; de ese modo, las relaciones existentes entre estos intereses no constituyen un bien en sí, sino solamente un medio de obtener los bienes particulares buscados por cada uno. La comunidad, en cambio, constituye un bien intrínseco para todos los que forman parte de ella; sea a nivel de generalización psicológica descriptiva - los seres humanos tienen necesidad de pertenecer a una comunidad-, sea como generalización normativa - la comunidad es un bien objetivo para los seres humanos- $-{ }^{34}$. «No hay duda entonces para los comunitaristas, de que si el hombre moderno está hoy buscándose a sí mismo sin tregua, es precisamente porque su identidad no está constituida por nada» ${ }^{35}$.

Desde el punto de vista político, el movimiento comunitarista, es difícilmente clasificable ${ }^{36}$. En algunos de sus aspectos, como la importancia que da a las normas "premodernas» y a las tradiciones, parece próximo a un cierto conservadurismo republicano. Por otro lado, al compartir algunas aspiraciones políticas del socialismo clásico, y dar prioridad a los factores sociales sobre las determinaciones individuales, explica que alguna vez se le haya relacionado con los escritos del joven Marx ${ }^{37}$. Walzer señala cómo la crítica comunitaria del liberalismo puede reforzar las viejas desigualdades propias de los modos de vida tradicionales o, al contrario, corregir las nuevas desigualdades debidas al mercado liberal y a la burocracia estatal ${ }^{38}$. La misma ambivalencia se encuentra a nivel de los autores.

En el plano sociológico se puede señalar la fuerte resonancia que ha tenido en los medios feministas, en ciertas corrientes «multiculturalistas»-el comunitarismo como base de defensa de los derechos de las minorías contra el modelo asimilacionista dominante- y en el movimiento ecologista, como terreno privilegiado de resistencia a las prácticas de las burocracias institucionales y a la extensión de mercados globales.

Casi todos los comunitaristas critican la idea de ciudadanía económi$c a$, que reduce a los miembros de la sociedad a «espectadores que votan» y «consumidores siempre deseosos de mejorar su posición en el mercado». Muchos critican el centralismo, la burocracia estatal y buscan formas variadas de democracia participativa. Hay un sentir común respecto a que si no podemos volver a dar vida a las comunidades orgánicas ordenadas a la idea de bien común y valores compartidos, la sociedad no tendrá otra 


\section{Concepción Naval y Alejo José G. Sison}

alternativa que el autoritarismo o la desintegración. De este modo, unos se proponen revitalizar las tradiciones, otros subrayan la importancia de los bienes públicos y de los equipamientos colectivos y otros reclaman una tradición de «republicanismo cívico» que remonta a la Antigüedad y ha conocido su apogeo en las repúblicas italianas de fines de la Edad Media antes de jugar un papel también en las revoluciones francesa y americana. En los EE.UU. esta tradición recurre tanto a Maquiavelo y $\mathrm{H}$. Arendt como a T. Jefferson, P. Henry y J. Dewey ${ }^{39}$. Ocupan un lugar privilegiado las ideas de renovación de una ciudadanía activa ${ }^{40}$, de reconocimiento $^{41}$ y de participación ${ }^{42}$.

En efecto, la tradición es la clave de la posible distinción -y no separación, porque en muchos puntos esenciales, se percibe más bien una continuidad - entre el comunitarismo norteamericano y el comunitarismo europeo. Por mucho que se hable de una «tradición liberal», en realidad, se trata de un sinsentido, porque las «doctrinas recibidas» necesarias para engendrar una tradición se descalifican de entrada como inadmisibles o inaceptables. Da lo mismo que estas «doctrinas recibidas» procedan del campo religioso o moral, de la física o de las matemáticas, de la política o de la sociología. Siempre serán "supersticiones», irracionales y extra-científicas, o lo que es peor, obstáculos para el consenso y motivos de discordia entre las personas.

Para el comunitarismo, en cambio, la tradición es el topos o «lugar propio» de la verdad, tanto en su vertiente teórica, como en la práctica. No es que una cosa sea verdad porque es «lo tradicional», como vendría a decir el "tradicionalismo», el "conservadurismo» o cualquier otro movimiento nostálgico. Una cosa es verdad, más bien, en gran parte, porque es capaz de dar a luz a una tradición. Y una tradición, si ha de ser auténtica, exige al menos un relato de la racionalidad (unos primeros principios, unas reglas para la dialéctica y la demostración verdaderas, la intencionalidad del conocimiento, etc.), de la naturaleza humana teleológica o finalizada, y de la polis, sociedad o «comunidad de vida» donde el desarrollo o el perfeccionamiento sea posible.

Se dice, con razón, que el comunitarismo se ha originado en suelo norteamericano, como resultado de las reflexiones de pensadores norteamericanos sobre los problemas particulares de su sociedad. Pero el fenómeno comunitarista no hubiera sido posible si no fuera por la herencia europea - sobre todo, en la filosofía política- de aquellos pensadores. Al fin y al cabo, se trataba o de europeos trasplantados en la sociedad norteamericana, o de norteamericanos embebidos por la civilización y la cultura europeas, convenientemente modificadas según sus circunstancias. Es decir, ni la problemática ni la propuesta comunitarista podría haber 
que tales, fines comunes ligados a los valores o a las experiencias comrtidas, y no solamente a intereses privados más o menos congruentes. stos fines son propios de la comunidad misma, no son objetivos partillares que resultan ser los mismos en la mayor parte de sus miembros. $\mathrm{n}$ una simple asociación, los individuos miran sus intereses como indeendientes y potencialmente divergentes los unos de los otros; de ese ıodo, las relaciones existentes entre estos intereses no constituyen un ien en sí, sino solamente un medio de obtener los bienes particulares uscados por cada uno. La comunidad, en cambio, constituye un bien ntrínseco para todos los que forman parte de ella; sea a nivel de generalización psicológica descriptiva - los seres humanos tienen necesidad de pertenecer a una comunidad-, sea como generalización normativa - la comunidad es un bien objetivo para los seres humanos - ${ }^{34}$. «No hay duda entonces para los comunitaristas, de que si el hombre moderno está hoy buscándose a sí mismo sin tregua, es precisamente porque su identidad no está constituida por nada $»^{35}$.

Desde el punto de vista político, el movimiento comunitarista, es difícilmente clasificable ${ }^{36}$. En algunos de sus aspectos, como la importancia que da a las normas "premodernas» y a las tradiciones, parece próximo a un cierto conservadurismo republicano. Por otro lado, al compartir algunas aspiraciones políticas del socialismo clásico, y dar prioridad a los factores sociales sobre las determinaciones individuales, explica que alguna vez se le haya relacionado con los escritos del joven Marx ${ }^{37}$. Walzer señala cómo la crítica comunitaria del liberalismo puede reforzar las viejas desigualdades propias de los modos de vida tradicionales o, al contrario, corregir las nuevas desigualdades debidas al mercado liberal y a la burocracia estatal ${ }^{38}$. La misma ambivalencia se encuentra a nivel de los autores.

En el plano sociológico se puede señalar la fuerte resonancia que ha tenido en los medios feministas, en ciertas corrientes «multiculturalistas» - el comunitarismo como base de defensa de los derechos de las minorías contra el modelo asimilacionista dominante- y en el movimiento ecologista, como terreno privilegiado de resistencia a las prácticas de las burocracias institucionales y a la extensión de mercados globales.

Casi todos los comunitaristas critican la idea de ciudadanía económi$c a$, que reduce a los miembros de la sociedad a «espectadores que votan» y "consumidores siempre deseosos de mejorar su posición en el mercado». Muchos critican el centralismo, la burocracia estatal y buscan formas variadas de democracia participativa. Hay un sentir común respecto a que si no podemos volver a dar vida a las comunidades orgánicas ordenadas a la idea de bien común y valores compartidos, la sociedad no tendrá otra 
to que tales, fines comunes ligados a los valores o a las experiencias compartidas, y no solamente a intereses privados más o menos congruentes. Estos fines son propios de la comunidad misma, no son objetivos particulares que resultan ser los mismos en la mayor parte de sus miembros. En una simple asociación, los individuos miran sus intereses como independientes y potencialmente divergentes los unos de los otros; de ese modo, las relaciones existentes entre estos intereses no constituyen un bien en sí, sino solamente un medio de obtener los bienes particulares buscados por cada uno. La comunidad, en cambio, constituye un bien intrínseco para todos los que forman parte de ella; sea a nivel de generalización psicológica descriptiva - los seres humanos tienen necesidad de pertenecer a una comunidad-, sea como generalización normativa - la comunidad es un bien objetivo para los seres humanos- ${ }^{34}$. «No hay duda entonces para los comunitaristas, de que si el hombre moderno está hoy buscándose a sí mismo sin tregua, es precisamente porque su identidad no está constituida por nada $»^{35}$.

Desde el punto de vista político, el movimiento comunitarista, es difícilmente clasificable ${ }^{36}$. En algunos de sus aspectos, como la importancia que da a las normas «premodernas» y a las tradiciones, parece próximo a un cierto conservadurismo republicano. Por otro lado, al compartir algunas aspiraciones políticas del socialismo clásico, y dar prioridad a los factores sociales sobre las determinaciones individuales, explica que alguna vez se le haya relacionado con los escritos del joven Marx ${ }^{37}$. Walzer señala cómo la crítica comunitaria del liberalismo puede reforzar las viejas desigualdades propias de los modos de vida tradicionales o, al contrario, corregir las nuevas desigualdades debidas al mercado liberal y a la burocracia estatal ${ }^{38}$. La misma ambivalencia se encuentra a nivel de los autores.

En el plano sociológico se puede señalar la fuerte resonancia que ha tenido en los medios feministas, en ciertas corrientes «multiculturalistas» - el comunitarismo como base de defensa de los derechos de las minorías contra el modelo asimilacionista dominante- y en el movimiento ecologista, como terreno privilegiado de resistencia a las prácticas de las burocracias institucionales y a la extensión de mercados globales.

Casi todos los comunitaristas critican la idea de ciudadanía económi$c a$, que reduce a los miembros de la sociedad a «espectadores que votan» y «consumidores siempre deseosos de mejorar su posición en el mercado». Muchos critican el centralismo, la burocracia estatal y buscan formas variadas de democracia participativa. Hay un sentir común respecto a que si no podemos volver a dar vida a las comunidades orgánicas ordenadas a la idea de bien común y valores compartidos, la sociedad no tendrá otra 
R.B., The Dance with Community: The Contemporary Debate in American Political Thought, University of Kansas City, Kansas City, 1991; AVINERI, S. and DE-SHALIT, A., eds., Communitarianism and Individualism, Oxford University Press, Oxford, 1992; GUTMANN, A., ed., Multiculturalism and the Politics of Recognition, Princeton University Press, New Yersey, 1992; Daly, M., ed, Communitarianism. A New Public Ethics, Wadsworth Publishing Company, Belmont, California, A Division of Wadsworth, Inc, 1994; RASMUSSEN, D., ed., Universalism vs. Communitarianism, Contemporary Debates in Ethics, MIT Press, Cambridge, Massachusetts, London, England, 1990; BELL, D., Communitarianism and its Critics, Clarendon Press, Oxford, 1993, Demain, J. \& H. EnTwistle, eds., Beyond Communitarianism. Citizenship, Politics and Education, Macmillan, London, 1996, PEREZ ADAN, J., «Comunitarismo, moralidad política y la crítica al neoaristotelismo emergente", Sistema, 142, 1998, pp. 87-104 y La salud social, Trotta, Madrid, 1999.

26 Avineri\&De-Shalt señalan las dos esferas en las que es posible situar al comunitarismo: la metodológica y la normativa (cfr. o.c., pp. 2-11).

27 Cfr. A. Macintyre, After Virtue, University of Notre Dame Press, Notre Dame, 1981, pp. 236 y 251. También A. de BenoIsT, o.c., p. 11.

28 Cfr. o.c., "Preface: We, the Communitarians", pp. iii-vi. Sandel distingue la línea de separación entre individualismo y comunitarismo, afirmando que el liberalismo, en cuanto es individualista es la política de los derechos (rights) —cómo limitar la esfera de lo político-, mientras que el comunitarismo es la política del bien común (common good) - cómo extender la esfera de lo político-. Pero esta distinción quizá no es tan obvia porque uno puede argumentar que el bien común en las sociedades liberales occidentales es la neutralidad y las libertades básicas; de aquí que el liberalismo no cortaría las demandas del liberalismo (cfr. AvINERI, S. and DE-SHALIT, A., eds., Communitarianism and Individualism, Oxford University Press, Oxford, 1992, pp. 7-8).

29 Cfr. BUChANAN, A., "Assesing Communitarian Critique of Liberalism", Ethics, 99, 1989, pp. 852-882 y Holmes, S., The Anatomy of Antiliberalism, Harvard University Press, Cambridge, 1993.

30 Cfr. al respecto, W. KYMLICKA, "Liberalism and Communitarianism", Canadian Journal of Philosophy, 18/2, 1988, pp. 181-204, donde expone el razonamiento comunitarista al argumentar por qué falla la defensa que los liberales hacen del concepto de yo. Contrasta (cfr. p. 191) el punto de vista comunitario del razonamiento moral como autodescubrimiento con el liberal como juicio. Distingue entre liberales kantianos como Rawls y Dworkin, y liberales hegelianos, como Dewey.

31 Sobre este punto cfr. SANDEL, M. J., Liberalism and Its Critics, Basil Blackwell, Oxford, 1984, pp. 31 y 183.

32 Cfr. RORTy, R., Contingency, Irony and Solidarity, Cambridge University Press, Cambridge, 1989 y el comentario de A. MacIntyre a esta obra en The Journal of Philosophy, 87, 1990, pp. 708-711.

33 Cfr. "The priority of Democracy to Philosophy» in M. PETERSON and R. VAughan, eds., The Virginia Statute for Religious Freedom, Madison, Wisconsin, 1988.

34 Cfr. R. Mangabeira Unger, Knowledge and Politics, Free Press, New York, 1975, p. 102 y cfr. M. WALZER, Spheres of Justice. A Defense of Pluralism and Equality, Princeton University Press, Princeton, 1983.

35 A. de BENOIST, o.c., p. 18.

36 Cfr. en este punto la crítica de B. Barber al libro de Fowler, The Dance with Community, en The Responsive Community, winter 1992/93, 3, pp. 85-88, donde distingue comunitaristas conservadores que subrayan las cargas tradicionales de los grupos y que 


\section{Las propuestas comunitaristas en América y en Europa}

ne a la interpretación de que la sociedad es tan reaỉ como los individuos, una interpretación a la que llamamos realismo social y que es común a las tradiciones bíblica y republicana".

13 Cfr. MACPherson, C.B., Democratic Theory. Essays in Retrieval, Clarendon Press, Oxford, 1973, p. 199, y K. A. STRIKE, «Community and Individualism: Two Views», Studies in Philosophy and Education, 12/1, 1993, pp. 11-19.

14 Cfr. Ch. LARMORE, Modernité et morale, PUF, Paris, 1993, p. 46. H. Sidgwick (The Methodes of Ethics, Macmillan, London, 1874) partidario del utilitarismo, se le considera como uno de los más importantes representantes de la filosofía moral anglo-sajona de la segunda mitad del s. XIX. Rawls lo cita elogiosamente.

15 Para Kant, sólo la buena voluntad es incondicionalmente buena, es decir la disposición que nos empuja a obrar de acuerdo con el principio moral, independientemente de toda idea de acabamiento de sí.

16 RAwLs, J., A Theory of Justice, Harvard University Press, 1971; Oxford University Press, Oxford, 1971, p. 92-93. Cfr. «Justicia como imparcialidad: política, no metafísica", Diálogo Filosófico, 16, 1990, pp. 4-32.

17 Cfr. RAwLS, J., A Theory of Justice, o.c.; «Justicia como imparcialidad: política, no metafísica», o.c.; "The idea of an overlapping consensus", Oxford Journal of Legal Studies, 7, 1987, pp.1-25; "The domain of the political and overlapping consensus", New York University Law Review, 64/2, 1989, pp. 233-255; Political Liberalism, Columbia University Press, New York, 1993.

18 Cfr. BONETE, E., "La noción de persona moral en la teoría ético-política de Rawls", Sistema, 85, 1988, pp. 63-85 y F. VALLESPIN, Nuevas teorías del contrato social: J. Rawls, R. Nozick y J. Buchanan, Alianza Editorial, Madrid, 1985.

19 A. Bloom en su obra Giants and Dwarfs, hace una dura crítica al punto de vista de Rawls: cfr. "La justicia: John Rawls contra la tradición de la filosofía política» (Simon\&Schuster, New York, 1990).

20 Political Liberalism, Columbia University Press, New York, 1993. Cfr. el comentario a esta obra - con referencia a Theory of Justice (1971)- realizada por HitTINGER, R., "John Rawls, Political Liberalism», Review of Metaphysics, 47, 1994, pp. 585-602.

21 Nozick incluso afirma que «no existe ninguna entidad social en la que el bien sea tal que justifique un sacrificio en tanto que tal. No hay más que individuos, individuos diferentes, que llevan vidas individuales» (NozICK, R., Anarchy, State and Utopia, Blackwell, Oxford, 1974, pp. 32-33).

22 Cfr. SANDEL, M., Liberalism and Its Critics, Basil Blackwell, Oxford, 1984, p. 4.

23 Cfr. Fowler, R. B., The Dance with Community: The Contemporary Debate in American Political Thought, University of Kansas City, Kansas City, 1991 y el libro de A. ETZIONI, ed., Rights and the Common Good. The communitarian perspective, St. Martin's Press, New York, 1995, que el editor presenta como: «the intellectual framework of the communitarian approach, about communitarian ideas and concepts, the questions that challenge communitarian thinking, and the answers it is groping with" (p. VI). También C. THIEBAUT, Los limites de la comunidad, Centro de Estudios Constitucionales, Madrid, 1993.

24 Cfr. EtzIoni, A., Rights and the Common Good. The communitarian perspective donde señala: «More reciently, the term - communitarian- has been associated with the works of Charles Taylor, Hans Joas, Jonathan Boswell, Adam Swift, Michael Sandel, Michael Walzer and Philip Selznick, among others" (p.iii).

25 Una obra destacable para la comprensión de esta cuestión es la de MULHALL, S. \& SwIFT, A., Liberals \& Communitarians, Blackwell, Oxford, 1992. También KYMLICKA, W., Liberalism, Community and Culture, Oxford University Press, Oxford, 1989; FOWLER, 


\section{Las propuestas comunitaristas en América y en Europa}

ven la jerarquía como estructuras naturales de la comunidad (R. Nisbet); democráticos, para los cuales las comunidades son la condición para la igualdad social; nostálgicos, que creen que la era de la comunidad ha sido destruida por la modernidad; utópicos, que piensan la edad de la comunidad, como por venir; republicanos, algunos miran a la polis como modelo de política ideal; anarquistas que ven la política como enemigo de la comunidad. Paul Piccone señala: «En tanto que proyecto de reconstrucción social, el comunitarismo no está ligado ni a la derecha ni a la izquierda. En los años 30, constituyó un proyecto de izquierda donde el New Deal ha constituido el punto culminante, en tanto que en los años 80 , la derecha se ha amparado en él para traducirlo en los éxitos electorales que han acompañado la "revolución» reaganiana. Hoy, las dos grandes partes hacen referencia a él y a los valores que encarna para dar un fundamento a sus programas respectivos" ("Roundtable on Communitarianism», Telos, 1988, p. 3)

37 W. KYMLICKA mantiene una opinión diversa al respecto: cfr. Liberalism, Community and Culture, Oxford University Press, Oxford, 1989, cap. 6: «Marxism and the Critique of Justice", pp. 100-131. Ver también, Buchanan, A., Marx and Justice. The Radical Critique of Liberalism, Methuen, London, 1982.

38 "The Communitarian Critique of Liberalism", Political Theory, 18, 1, 1990, p. 23. Cfr. E.G. Martínez Navarro, «La polémica de Rawls con los comunitaristas», Sistema, 107, 1992, pp. 55-72.

39 Cfr. Pocock, J. G. A., The Machiavelliam Moment. Florentine Political Thought and the Atlantic Republican Tradition, Princeton University Press, Princeton, 1975; "Machiavelli in the liberal cosmos", Political Theory, 13/4, 1985, pp. 559-574. También F. INCIARTE, «Reflexiones sobre el republicanismo», Thémata. Revista de Filosofía, 10, 1992, pp. 501-515. El republicanismo cívico se ve a sí mismo como una alternativa, un tercer camino entre el liberalismo y el comunitarismo, y comparte con cada uno de ellos algún punto, a la vez que disiente en otros.Ver también SkINNER, Q., The Foundations of Modern Political Thought, 2 vols., Cambridge University Press, Cambridge, 1978.

40 Cfr. J. M. Rosales, «Democracia y solidaridad. Rudimentos para una ciudadanía democrática", Sistema, 107, 1992, pp. 83-93.

41 Cfr. Ch. TAYLOR, «The Politics of Recognition", en Gutmann, A., ed., Multiculturalism and the Politics of Recognition, Princeton University Press, New Yersey, 1992, pp. 2573, y el comentario que hace M. Walzer, pp. 99-104, así como la introducción de la editora.

42 Cfr. Barber, B., Strong Democracy: Participatory Politics for a New Age, University California Press, Berkeley, California, 1984. Así escribe Ch. Taylor que la noción central del humanismo cívico, es que los hombres encuentren su bien en la vida pública de una república de ciudadanos. El comunitarismo entonces, parece desembocar en un abandono de la causa de la nación-estado y una renovación de la idea federalista. Cfr. M. Gauchet, "Le mal démocratic", Esprit, X.1993, p. 82 y P. Piccone, "The Crisis of liberalism and the Emergence of Federal Populism", Telos, Fall 1991, pp. 7-44, que apunta a la creación de pequeñas comunidades orgánicas autónomas permitiendo la instauración de una verdadera democracia participativa en el interior de un marco federal.

\section{Bibliografía}

IVINERI, S. AND DE-Shalit, A., eds. Communitarianism and Individualism. Oxford University Press. Oxford. 1992. 


\section{Concepción Naval y Alejo José G. Sison}

Barber, B. Strong Democracy: Participatory Politics for a New Age. University California Press. Berkeley. California. 1984.

Bell, D. Communitarianism and its Critics. Clarendon Press. Oxford. 1993.

BeLlaH, R. Y COL. Habits of the Heart. University of California Press. Berkeley. California. 1985.

BENOIST, A. DE. «Communautariens vs libéraux» en Krisis. monográfico «Communauté?». 16, 1994, pp. 1-29.

BLOOM, A. «La justicia: John Rawls contra la tradición de la fỉosofía política». Giants and Dwarfs. Simon\&Schuster. New York. 1990.

BONETE, E. «La noción de persona moral en la teoría ético-política de Rawls». Sistema. 85, 1988, pp. 63-85.

Buchanan, A. Marx and Justice. The Radical Critique of Liberalism. Methuen. London. 1982.

"Assesing Communitarian Critique of Liberalism». Ethics. 99, 1989, pp. 852-882.

Daly, M., ed. Communitarianism. A New Public Ethics. Wadsworth Publishing Company. Belmont. California. 1994

Demain, J. \& Entwistle, H., eds. Beyond Communitarianism. Citizenship, Politics and Education. Macmillan. London. 1996.

Etzioni, A., ed. Rights and the Common Good. The communitarian perspective. St. Martin's Press. New York. 1995.

The New Golden Rule: Community and Morality in a Democratic Society. Basic Books. New York. 1996.

Fowler, R.B. The Dance with Community: The Contemporary Debate in American Political Thought. University of Kansas City. Kansas City. 1991.

GadAmer, H.G. Verdad y método. Sígueme. Salamanca. 1977.

Gutmann, A. "Communitarian Critics of Liberalism». Philosophy and Publics Affairs. 14/3. 1985.

Gutmann, A., ed. Multiculturalism and the Politics of Recognition. Princeton University Press. New Jersey. 1992.

Hittinger, R. «John Rawls. Political Liberalism». Review of Metaphysics. 47, 1994, pp. 585-602.

INCIARTE, F., «Reflexiones sobre el republicanismo». Thémata. Revista de Filosofía. 10, 1992 , pp. 501-515.

KymliCKA, W. "Liberalism and Communitarianism». Canadian Journal of Philosophy. 18/2. 1988. pp. 181-204.

Liberalism. Community and Culture. Oxford University Press. Oxford. 1989.

LASH, Ch. The True and Only Heaven. Progress and its Critics. W.W. Norton. New York. 1991.

Macintyre, A. After Virtue. University of Notre Dame Press. Notre Dame. 1981.

Mangabeira Unger, R. Knowledge and Politics. Free Press. New York. 1975.

MARTINEZ NAVARRO, E.G. "La polémica de Rawls con los comunitaristas». Sistema. 107. 1992. pp. 55-72.

Mulhall, S. \& Swift, A.. Liberals \& Communitarians. Blackwell. Oxford. 1992.

NAVAL, C. Educar ciudadanos. La polémica liberal-comunitarista en educación. EUNSA. Pamplona. 1995.

NisBet, R. The Quest for Community. Oxford University Press. Oxford. 1953.

NozICK, R. Anarchy, State and Utopia. Blackwell. Oxford. 1974.

PEREZ ADAN, J. «Comunitarismo, moralidad política y la crítica al neoaristotelismo emergente». Sistema. 142. 1998. pp. 87-104. 


\section{Las propuestas comunitaristas en América y en Europa}

La salud social. Trotta. Madrid. 1999.

PICCONE, P. «Roundtable on Communitarianism». Telos. 1988.

"The Crisis of liberalism and the Emergence of Federal Populism». Telos. 1991. pp. 7-44.

Pocock, J.G.A. The Machiavelliam Moment. Florentine Political Thought and the Atlantic Republican Tradition. Princeton University Press. Princeton. 1975.

"Machiavelli in the liberal cosmos». Political Theory. 13/4. 1985. pp. 559-574.

Rasmussen, D., ed. Universalism vs. Communitarianism. Contemporary Debates in Ethics. MIT Press. Cambridge. Massachusetts. London. England. 1990.

RAwLs, J. A. Theory of Justice. Harvard University Press. Oxford University Press. Oxford. 1971.

«Justicia como imparcialidad: política, no metafísica». Diálogo Filosófico. 16. 1990. pp. 4-32.

«The idea of an overlapping consensus». Oxford Journal of Legal Studies. 7. 1987. pp. 1-25.

Political Liberalism. Columbia University Press. New York. 1993.

REDFIELD, R. The Little Community. Viewpoints for the Study of a Human Whole. University of Chicago Press. Chicago. 1955.

RoRTy, R. Philosophy and the mirror of nature. Princeton. Princeton University Press. 1979. p. 368.

"The priority of Democracy to Philosophy", en M. Peterson and R. Vaughan. eds. The Virginia Statute for Religious Freedom. Madison. Wisconsin. 1988.

Contingency, Irony and Solidarity. Cambridge University Press. Cambridge. 1989.

ROSAlEs, J.M. «Democracia y solidaridad. Rudimentos para una ciudadanía democrática". Sistema. 107. 1992. pp. 83-93.

"Apuntes para una modernidad revisada: Habermas y el proyecto de la racionalidad comunicativa". Thémata. Revista de Filosofía. 11. 1993. p. 174.

SANDEL, M.J. Liberalism and Its Critics. Basil Blackwell. Oxford. 1984.

SkInNer, Q. The Foundations of Modern Political Thought. 2 vols. Cambridge University Press. Cambridge. 1978.

StrIKe, K. A., "Community and Individualism: Two Views". Studies in Philosophy and Education. 12/1. 1993.

TAYLOR, Ch. "The Politics of Recognition". en Gutmann. A. ed. Multiculturalism and the Politics of Recognition. Princeton University Press. New Yersey. 1992. pp. 25-73.

Thiebaut, C. Los limites de la comunidad. Centro de Estudios Constitucionales. Madrid. 1993.

Vallespin, F. Nuevas teorias del contrato social: J. Rawls. R. Nozick y J. Buchanan. Alianza Editorial. Madrid. 1985.

Walzer, M. Spheres of Justice. A Defense of Pluralism and Equality. Princeton University Press. Princeton. 1983.

"The Communitarian Critique of Liberalism». Political Theory. 18, 1, 1990, p. 23. 